\title{
Head Scurf pin Aspiration, A sub type of Foreign Body Aspiration
}

\author{
Ihssan Ali Hais Elamery (MBChB,FICMS) ${ }^{1}$
}

Abstract

Background: Scurf pin inhalation is serious problem especially in muslim girls, who wear head cover and holding the pin by using her teeth or lips during wearing her scurf or laughing or coughing leading to accidental foreign body aspiration. Rigid Bronchoscopy is the treatment of choice and rarely surgery is needed.

Objective:To study a presentation, management and prognosis of those patient.

Patients and Methods: A retrospective study involving the patients with a history of pin aspiration conducted at the department of thoracic surgery, Imam Hussein medical city in kerbala for Dec. 2012 till Dec. 2017.

Results: 262 patients are included. The pins were removed by using rigid bronchoscopy in 251 cases safely without any complications ,4patients were coughed the pin before enter the theatre room $\& 7$ patients were coughed and swallowed it in digestive tract.

Conclusion: Scurf pin aspiration is a common problem in Iraqi Muslim females who wear Hijab. It can be easily preventable by health education and/or newly fashioned scarves that do not need pins for fixation but use press studs or something else. The left main bronchus is the site were the pin is commonly impacted and Rigid bronchoscope is mostly used for pin removal.

Keywords: Head scurf pin aspiration, Bronchoscopy.

Corresponding Author: ihsanalihais@ gmail.com

Received: $22^{\text {th }}$ January 2019

Accepted: $24^{\text {th }}$ April 2019

\footnotetext{
${ }^{1}$ Imam Hussein Medical city- Kerbala- Iraq.
}

\section{Introduction}

Foreign body aspirations (F.B) into the tracheobronchial tree can result in significant morbidity and mortality [1]. Scarf pin aspiration is a form of foreign body aspersion effecting specially young Muslim women [2]. Our patients include women who wear headscarves and putting the pin between their teeth before securing the veils. Aspiration usually occurs when they talking, laughing, and coughing [3].

Although the most common site for foreign body aspiration is the right main bronchus, the pins often settle in the left bronchus. Many theories discussed this finding to the Bernoulli phenomenon, when the patient coughing, laughing, or talking 
creates strong negative pressure inside the narrow left main bronchus than in the wide right main bronchus [4].

Symptoms of pin aspiration range from coughing, wheezing and dyspnea to hemoptysis. diagnosis is confirmed by chest radiography as the pins are radio-opaque and easily recognizes plain chest X-ray, which appear as linear metallic opacities [5]. Pins aspiration is usually removed by either rigid or flexible bronchoscope, flexible bronchoscopy is technically easier, but of limited value In children and infants, because the ventilation is difficult and the bronchoscope must at times be interrupted. Rigid bronchoscopy provides good visualization with continuous ventilation during operation,there for it is prefer for removal of foreign bodies [6-8] if both flexible and rigid bronchoscopies are failed, thoracotomy with bronchotomy and/or resection of the affected lung segment lobe is required $[9,10,11,12,13]$.

\section{Patients and Methods}

A retrospective study included the patients with the history of scarf pin aspiration were admitted to thoracic department in Imam Hussein medical city during the last 5 years. Scarf pin aspiration was diagnosed by taking detailed history from the patient with proper physical examination to excluded any cardio respiratory disease including the onset time, duration of time from aspiration to presentation, and size and shape of the headscarf pin. After clinical evaluation, all patients underwent radiological work-up in the form of plain chest X-ray, both posterio- anterior (PA) and lateral views, to confirm the presence of the scarf pin within the tracheo-bronchial tree. Rigid bronchoscopy is done under general anesthesia. After choosing an appropriate sized scope, it is connected to the light source and by aid of the direct laryngoscope the bronchoscope is advanced from the mouth till it passes between the vocal cords. Then the laryngoscope is removed, and bronchoscope is slightly advanced in the trachea and the anesthesia machine is connected to the side port of the bronchoscope. The site of the scarf pin is localized, and if the pin is visualized, a crocodile forceps is advanced through the bronchoscope to grasp the pin. Patients who underwent rigid bronchoscope were remain in hospital for few hours after bronchoscopy and then discharge to home.

\section{Results}

The present study included 262 patients ranging in age from $9-45$ years, different age groups are shown in Figure(1) that shown high number of cases in aged 20 years, all patients had the same history, that while holding the pin between teeth or lips for fixing Hijab, and at that time a sudden episode of deep inspiration due to laughing, crying or hiccup followed by chocking due to pin inhalation. The diagnosis was made by using posterior-anterior and lateral chest radiographs.Figure(2) shows the signs and symptoms according to the site of the pin impaction. Rigid bronchoscope was successful in removing the pins in 251 no death occurred during rigid bronchoscopy. 


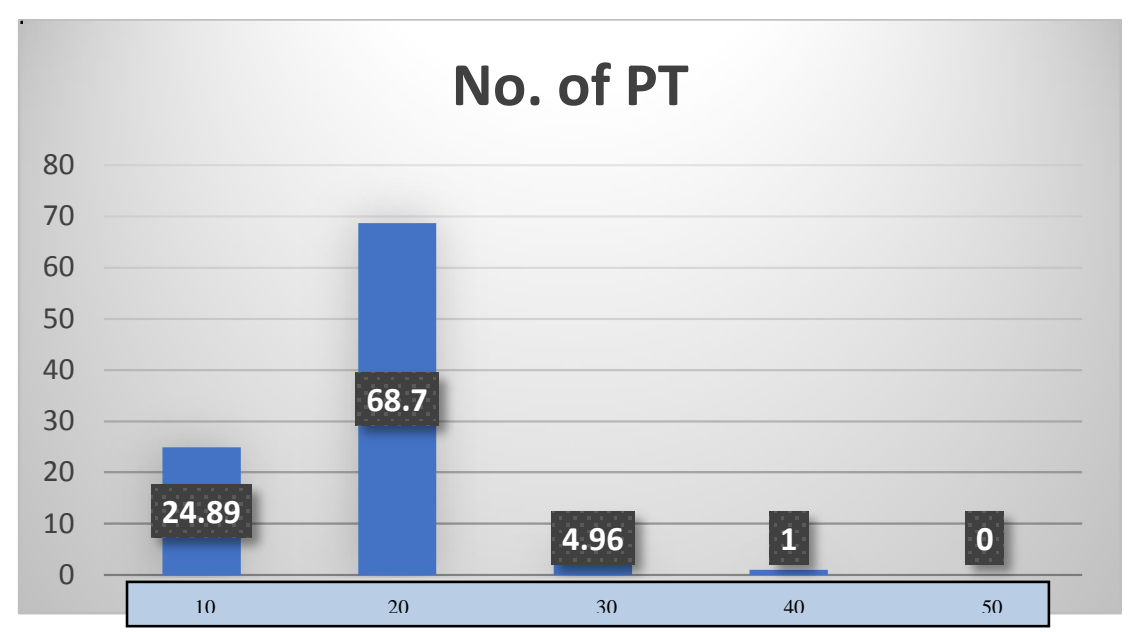

Figure(1):Number of patients according to age.

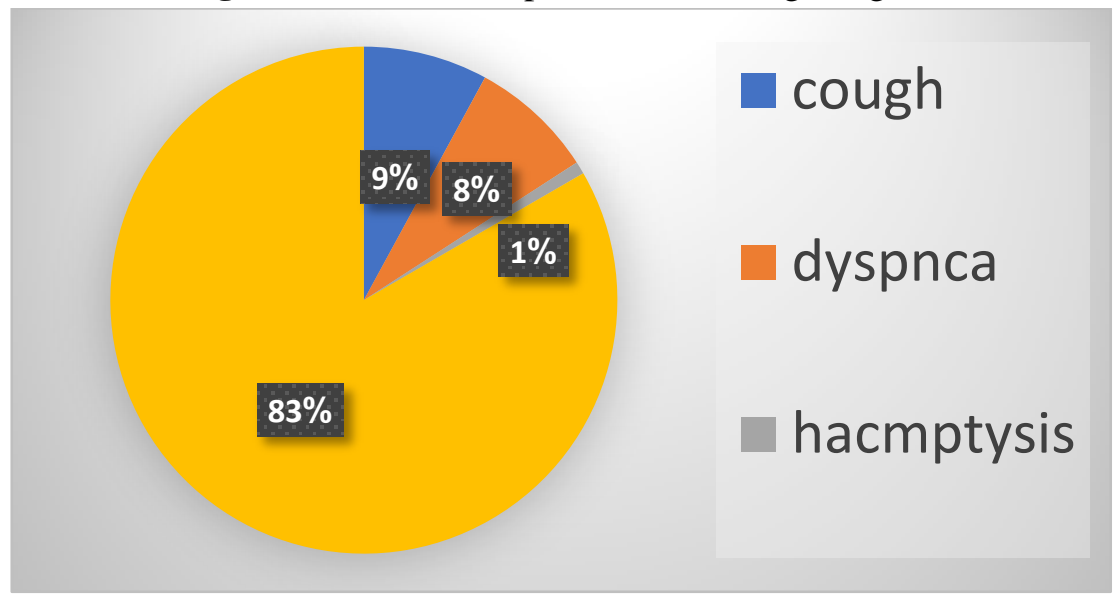

Figure(2): Presentation according to symptoms.

The number of cases according to years of patients and in another years 2015 shown56 presentation were shown in Figure(3), in 2017 patients, 2014 shown 47 patients and 2013 shown shown 63 patients while in 2016 revealed $61 \quad 35$ patients. 


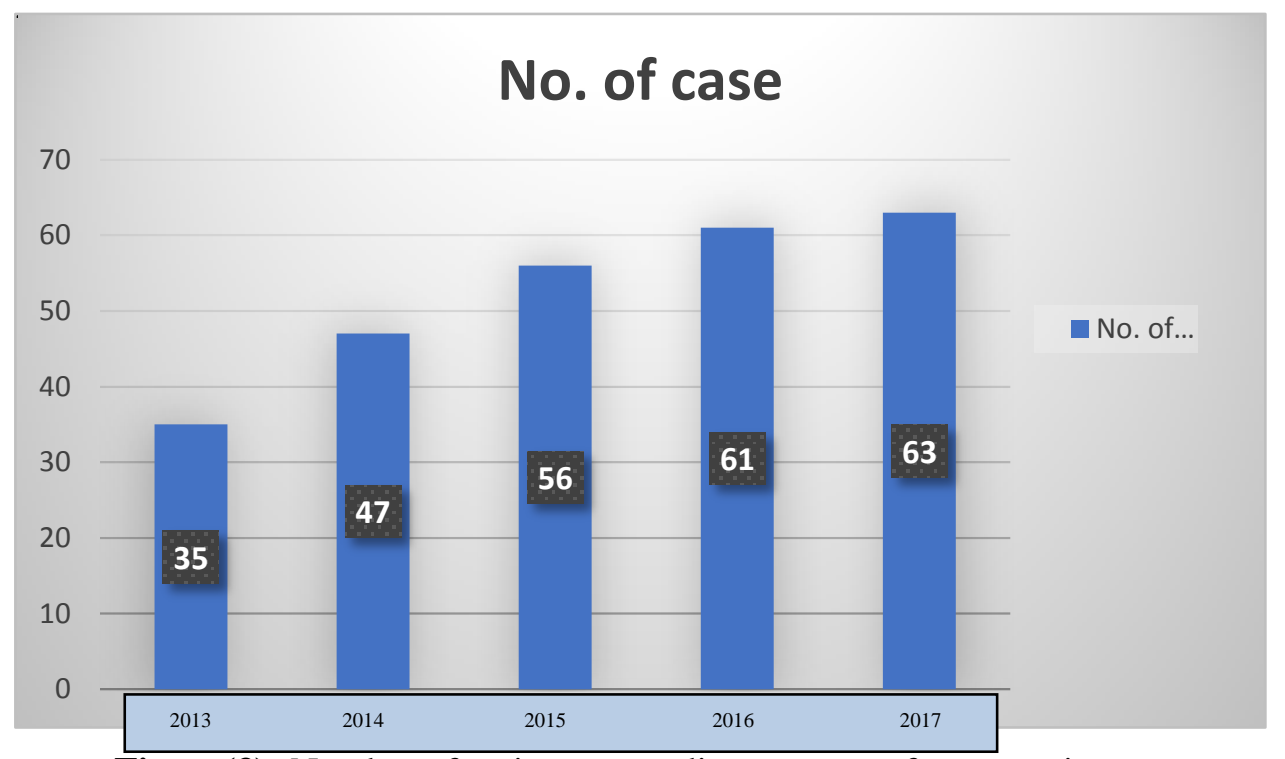

Figure(3): Number of patients according to years of presentation

Present study shown in Figure (4) the percentage of patients have impaction of pin number of patients according to site of in left lung (87\%), but in trachea (8\%) and impaction of pin, that revealed the high in right lung $(5 \%)$.

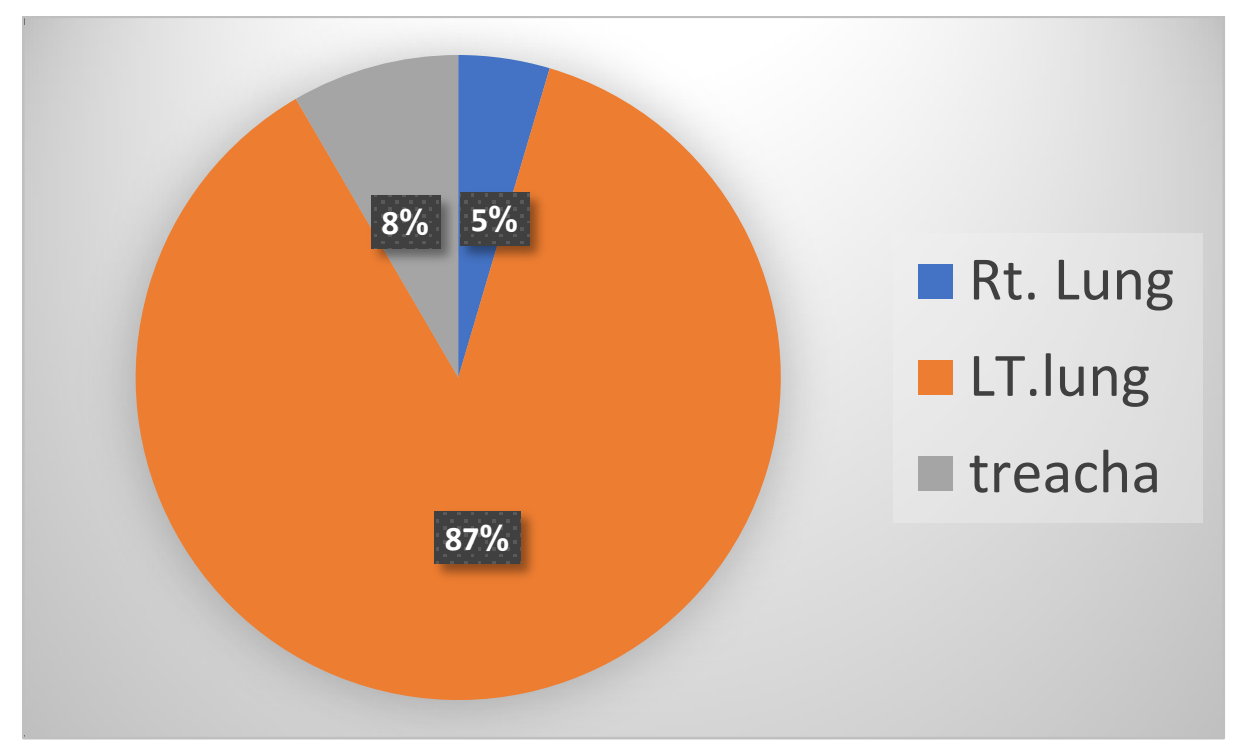

\section{Discussion}

Figure(4): Number of patients according to site of impaction of pin.

Scarf pin inhalation is a common and largely preventable a health problem in Muslim girls [14].Most of muslim women specially in teenage women in middle and south of Iraq because they lack experience tend to put the headscarf pin between their 
lips during securing the scarf veil. A sudden episode of laughing, coughing and talking that lead to aspiration. The headscarf pin is of variable length metallic pin with rounded plastic pearl of different colors [15] and may be use a fashion trend.the problem occur when the Girls use the pin as habitual behavior to put pins between the teeth adjust the headscarf.In our study, the median age was 13 years. Signs and symptoms of the scarf pin aspiration were coughed although most cases are symptoms less with adjustable history only [16]. However, a scarf pin is metallic and easily recognized by chest radiographs in figure 1 and 2 [17] and proper history after diagnosis was made, the scarf pins should be removed mostly by using rigid bronchoscopically where the pointed end should be grasped through the cavity of rigid bronchoscope by appropriate instruments to avoid injury to the mucosa of tracheobronchial tree.

\section{Conclusions}

Scarf pin inhalation is a common problem in Iraqi Muslim females who wear Hijab. It can be easily preventable by health education of women not to put-the pins between in the lips during wearing headscarves, or by using others types of headscarves that can be secure without using pins by using knots, clips, adhesive tapes and a snappers to secure the scarf and we ask a help other personal is working in media and those working as a religious to advices the to avoid using headscarves pin and use others types of hijab if they can avoid the habit of putting the pin between the lips during wearing the headscarves.although the headscarves pin aspirations may cause a big problem but its diagnosis can be made easy by proper history and plain chest X-ray examination.Bronchoscopy remains the treatment modality of choice in removal of pin inhalation.

\section{References}

[1] Swanson KL. Airway Foreign Bodies: What's New? Seminars in Respiratory andCritical Care Medicine 2004; 25(4): 405411.

[2]Hasdiraz L, Bicer C, Bilgin M, Oguzkaya F. Turban Pin Aspiration: NonAsphyxiating Tracheobronchial Foreign Body in Young Islamic Women. The Thoracic and cardiovascular surgeon. 2006; 54(4): 273-275.

[3]Rizk, N, Gwely, N, Biron, V Metallic hairpin inhalation: a healthcare problem facing young Muslim females. J Otolaryngol Head Neck Surg 2014; 43: 21-21. Google Scholar, Crossref, Medline. [4]Rizq, N, Gwely, N, Biron, V Metallic hairpin inhalation: a healthcare problem facing young Muslim females. J Otolaryngol Head Neck Surg 2014; 43: 21-21. Google Scholar, Crossref, Med. [5] Fenane, H, Bouchikh, M, Bouti, K Scarf pin inhalation: clinical characteristics and surgical treatment. J Cardiothorac Surg 2015; 10: 61-61. Google Scholar, Crossref, Medline.

[6]IlanO,EliasharR,HirshorenN,HamdanK,G rossM.Turbanpinaspiration:new fashion, 
new syndrome. Laryngoscope 2012 Apr;122(4):916e9.

[7] Rizk N, Gwely NE, Biron VL, Hamza U. Metallic hairpin inhalation: a healthcare problem facing young Muslim females. J Otolaryngol Head Neck Surg 2014 Aug $2 ; 43: 21$.

[8] Dikensoy O, Usalan C, Filiz A. Foreign body aspiration: clinical utility of flexible bronchoscopy. Postgrad Med J 2002;78:399e403.

[9] Hasdiraz L, Bicer C, Bilgin M, Oguzkaya F. Turban Pin Aspiration: NonAsphyxiating Tracheobronchial Foreign Body in Young Islamic Women. The Thoracic and cardiovascular surgeon. Gencera M, Ceylana E, Koksalb 2006; 54(4): 273-275.

[10] Gencera M, Ceylana E, Koksalb N. Extraction of Pins from the Airway with Flexible Bronchoscopy. Respiration 2007; 74(6):674-679.

[11] Kikuchi R, Isowa N, Tokuyasu H, Kawasaki Y. Intraoperative migration of a nail from the left $\mathrm{B} 10 \mathrm{~b}$ to the main bronchus.Interact Cardio Vasc Thorac 2007; 6: 92-93.

[12] Gokirmak M, Hasanoglu HC, Koksal N, Yildirim Z, Hacievliyagil SS, Soysal O. Retrieving aspirated pins by flexible bronchoscopy. Journal of Bronchology 2002!

9(1):10-14.

[13] evi a hmeda i a an me $\quad \mathrm{S}$ arf pin aspirations that required thoracotomy and pulmonary resection. Turk J Emerg Med 2010;10(2):82-85. [14] Al-Sarraf, N, Jamal-Eddine, H, Khaja, F Headscarf pin tracheobronchial aspiration: a distinct clinical entity. Interact Cardiovasc Thorac Surg 2009; 9: 187-190. Google Scholar, Crossref, Medline .

[15]Ahmed IA, Utility of fiberoptic bronchoscopy for retrieval of aspirated headscarf pins, Eur Scientific Journal 2013; 19: 218-27.

[16] Gonullu H, Ozturk Y, Akay S, Boncu M, Erkan N. Turbanpin: anunusual cause of foreign body aspiration in young Islamic adult. Iran Red Crescent Med J 2014

Mar;16(3):e2975.

[17] Al-Sarraf, N, Jamal-Eddine, H, Khaja, F Headscarf pin tracheobronchial aspiration: a distinct clinical entity. Interact Cardiovasc Thorac Surg 2009; 9: 187-190. Google Scholar, Crossref, Medline. 